\title{
Study of Lipid Profile and Electrocardiographic Changes in Hypothyroid Patients
}

\author{
Dr. Snehal Mishra ${ }^{1}$, Dr. Vipin Patel ${ }^{1}$, Dr. Madhur Sharma ${ }^{1}$, Dr. Chetan Mathur ${ }^{2 *}$, Dr. R. K. Jha ${ }^{3}$
}

${ }^{1}$ Residents Department of General Medicine, SAMC and PGI, Indore - Ujjain State Highway, near MR 10, Crossing, Indore, Madhya Pradesh 453555, India

${ }^{2}$ Assistant Professor, Dept. of General Medicine, SAMC and PGI, Indore - Ujjain State Highway, near MR 10, Crossing, Indore, Madhya Pradesh 453555, India

${ }^{3}$ Professor and HOD, Department of General Medicine, SAMC and PGI, Indore - Ujjain State Highway, near MR 10, Crossing, Indore, Madhya Pradesh 453555, India

DOI: $10.36347 /$ sjams.2021.v09i03.023

| Received: 22.02.2021 | Accepted: 14.03.2021 | Published: 15.03.2021

*Corresponding author: Dr. Chetan Mathur

Abstract

Original Research Article

Background: The study was designed to explore lipid profile and electrocardiographic changes associated with thyroid dysfunctions. Materials and Methods: A total of 50 Newly diagnosed hypothyroid patients (who were not on any treatment or were on treatment for less than 3 months) were investigated with lipid profiles and electrocardiogram (ECG). Purposive sampling was used to recruit the desired sample from the population of patients that met inclusionexclusion criterion for the present observational study. The comparisons of lipid profile parameters and ECG changes was carried out statistically with respect to severity of hypothyroidism. Results: The study population comprised of males and females between the age group of 27-74 years and the mean age group in this study was 49.46 years. There was a female preponderance consisting of $82 \%$ of total study population. The commonest finding in our study was presence of Low voltage complex; accounting for $66 \%$ of population, followed by Sinus Bradycardia in $26 \%$ population. Evidence of dyslipidemia was noticed in $60 \%$ of population. The average total cholesterol with $(225.33 \pm 115.05 \mathrm{mg} / \mathrm{dl})$, mean serum LDL $(153 \pm 31.75 \mathrm{mg} / \mathrm{dl})$, the mean Triglyceride levels and ratio of LDL and HDL in patients with severe TSH was significantly elevated. Conclusion: Hypothyroidism has significant impact on both cardiovascular system as well as Lipid profile, being more common in female patients. The commonest electrocardiographic change noted in our study was presence of Low voltage complex followed by sinus bradycardia. Qtc interval was also prolonged in significant no. of patients. Mean cholesterol, serum LDL and serum TG levels were significantly elevated but the serum HDL was significantly reduced among severe grades of TSH as compared to mild and moderate grades of TSH and were statistically significant.

Keywords: Lipid Profile, Electrocardiographic Changes, serum LDL, hypothyroidism.

Copyright (C) 2021 The Author(s): This is an open-access article distributed under the terms of the Creative Commons Attribution 4.0 International License (CC BY-NC 4.0) which permits unrestricted use, distribution, and reproduction in any medium for non-commercial use provided the original author and source are credited.

\section{INTRODUCTION}

Thyroid disorder carries maximum burden amongst all endocrinopathies across the globe. In India, thyroid disorders are the second most common glandular disorder of the endocrine system and predominantly increasing among female gender [1].

Hypothyroidism is an endocrinopathy demarcated by lower level of circulating thyroid hormones and thus subsequent slowing down of metabolic processes [2].

Hypothyroidism refers to inadequate production of thyroid hormones and can occur as primary, secondary or tertiary endocrine disease. In primary hypothyroidism, T3 and T4 levels are abnormally low, and thyroid-stimulating hormone (TSH) is high. In secondary and tertiary hypothyroidism, both thyroid hormones and TSH are low [3-7].

T3 and T4 are secreted from the thyroid gland. Much of T3 is also made by peripheral conversion of T4 to T3. T3 has broad effects on metabolism and cardiovascular function in adult [4-8].

Thyroid hormones exert direct cellular effects on almost all tissues of the body. It causes multi organ dysfunction due to deranged metabolism [9]. 
Snehal Mishra et al; Sch J App Med Sci, Mar, 2021; 9(3): 404-409

Cardiovascular complications are some of the most significant and reproducible clinical findings related with thyroid disorder. The electrocardiography (ECG) of hypothyroidism classically illustrates sinus bradycardia with low voltage complex and ST and T wave anomaly. Besides that, hypothyroidism may be associated with atrioventricular and intraventricular conduction disturbances.

Dyslipidemia in conjunction with various other metabolic abnormalities have been found in thyroid disorder which in turn leads to development of insulin resistance \& oxidative stress via vicious cycle.

Hence, prompt diagnosis with respect to classical symptoms \& signs of hypothyroidism in conjunction with relevant lab investigations and thus subsequent initiation of appropriate thyroid hormone replacement can minimize the associated cardiovascular morbidities.

\section{Aims And OBJECTIVES}

1. To study the various ECG changes in Hypothyroidism.

2. To study the effect of Hypothyroidism on Lipid Profile.

\section{Materials ANd Methods}

The study was conducted in the Department of Medicine, Sri Aurobindo Medical College and Post Graduate Institute, Indore (M. P.), during the period from December 2018 to May, 2020. Patients of newly diagnosed hypothyroidism who were on treatment for less than 3 months aged between 25 and 74 years and of both the sexes that further met all the inclusion criteria were selected as subjects during specified schedule.

\section{Inclusion Criteria}

1. All cases of newly diagnosed hypothyroid presented to OPD/IPD of study center.

2. Patients on treatment for less than 3 months.

3. Patient of both sexes, male and female.

4. Given the written consent for participation in the study.

\section{Exclusion Criteria}

1. Patient below age of 25 years.

2. Failure to give written consent for participation in the study.

3. Patients with COPD, Severe Anaemia, Diabetes Mellitus or any other Endocrinal Disorder.

4. Patients taking medications that alter the Thyroid Function like Beta blockers, Lithium, OCP's, Steroids and Alcohol.

The selected demographic, clinical factors of hypothyroidism with respect to various ECG changes were analyzed statistically. Comparisons of lipid profile parameters, heart rate and various ECG changes were carried out statistically with respect to severity of hypothyroidism.

A parametric test, Independent sample t-test was used to identify the significance of mean differences of T3, T4 and TSH between newly diagnosed hypothyroid patients with and without dyslipidemia.

Non-parametric test, Pearson's Chi-Square test was used to analyze the qualitative data.

The probability value, $\mathrm{p}>0.05$ was considered as statistically insignificant but the probability value from $\mathrm{p}<0.06$ to $\mathrm{p}<0.08$ was considered as suggestively or poorly significant.

Nevertheless, the probability value from $\mathrm{p}<0.05$ to $\mathrm{p}<0.02$ was considered as statistically significant while from $\mathrm{p}<0.01$ to $\mathrm{p}<0.001$ was considered as statistically highly/strongly significant.

\section{RESULTS}

\section{AGE ANF GENDER DISTRIBUTION}

The age of all newly diagnosed hypothyroid patients $(\mathrm{N}=500)$ were obtained in the ranges from 27 to 74 years. The mean age (Mean \pm Standard Deviation) of all newly diagnosed hypothyroid patients were found to be $49.46 \pm 13.10$ years (Table-1).

Out of fifty cases of newly diagnosed hypothyroid, more than three-fourth $(82.0 \%)$ of the cases were found to be female (Table-2).

Table-1: Distribution of Patients According To Age

\begin{tabular}{|l|l|l|}
\hline Age of patient & Frequency $(\mathbf{N})$ & Percent $(\%)$ \\
\hline 25-45 year & 24 & 48.0 \\
\hline 46-65 year & 18 & 36.0 \\
\hline$>$ 65 year & 8 & 16.0 \\
\hline Total & $\mathbf{5 0}$ & $\mathbf{1 0 0 . 0}$ \\
\hline
\end{tabular}

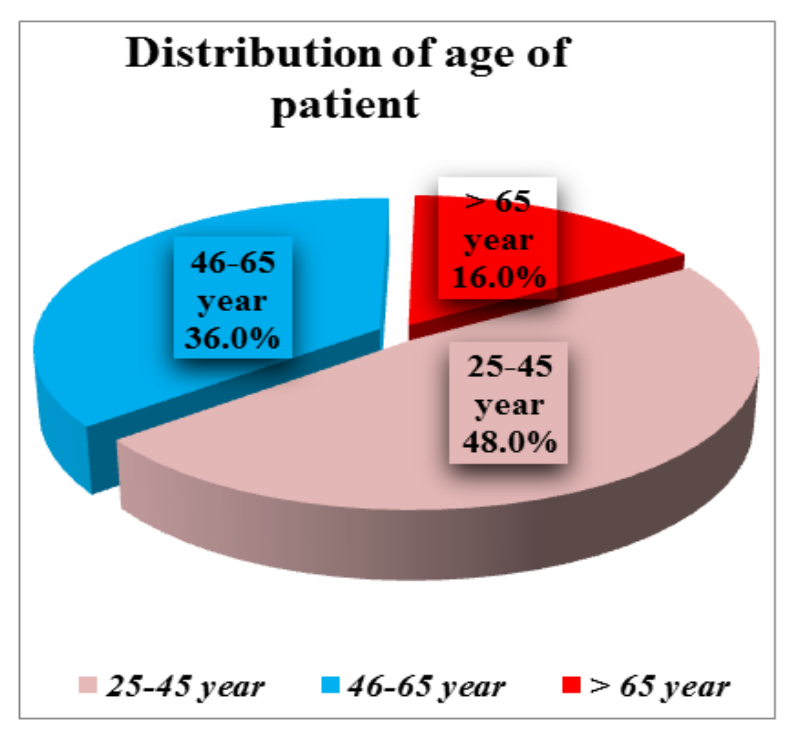


Snehal Mishra et al; Sch J App Med Sci, Mar, 2021; 9(3): 404-409

Table-2: Distribution of Patients According To Gender

\begin{tabular}{|l|l|l|}
\hline Gender & Frequency $\mathbf{( N )}$ & Percent $\mathbf{( \% )}$ \\
\hline Male & 9 & 18.0 \\
\hline Female & 41 & 82.0 \\
\hline Total & $\mathbf{5 0}$ & $\mathbf{1 0 0 . 0}$ \\
\hline
\end{tabular}

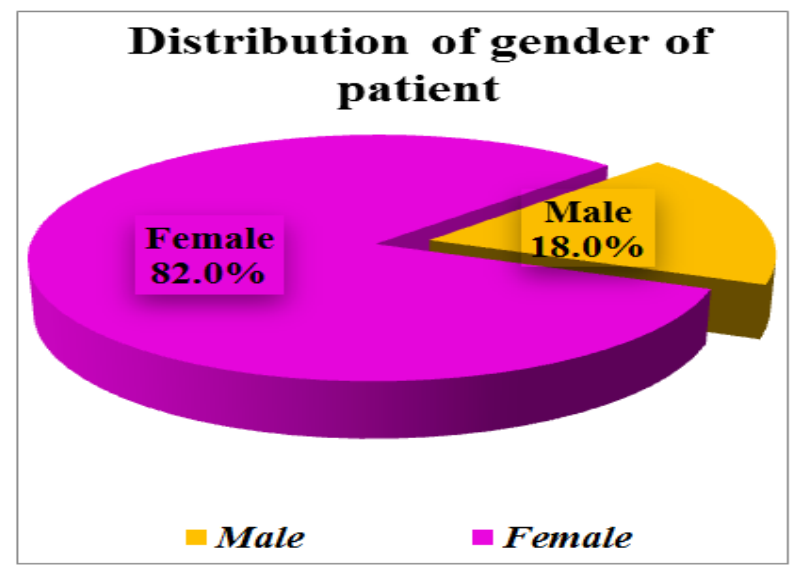

\section{LIPID PROFILE IN HYPOTHYROIDISM}

Severity of hypothyroidism was measured using laboratory value of thyroid stimulating hormone (TSH) at three levels such as mild, moderate and severe. Mild level of hypothyroidism was reported among those patients whose TSH was less than $20 \mathrm{mIU} / \mathrm{L}$ while from
20 to $50 \mathrm{mIU} / \mathrm{L}$ was considered as moderate level of hypothyroidism but the severe level of hypothyroidism was reported among those patients whose TSH was more than $50 \mathrm{mIU} / \mathrm{L}$.

Present enquiry revealed that the dyslipidemia found to be present among $60.0 \%$ newly diagnosed hypothyroid patients.

Table 3 and 4 reveals the assessment and comparison of total cholesterol, serum LDL and serum HDL and serum TG of patients with respect to three grades of thyroid stimulating hormone (mild, moderate and severe).

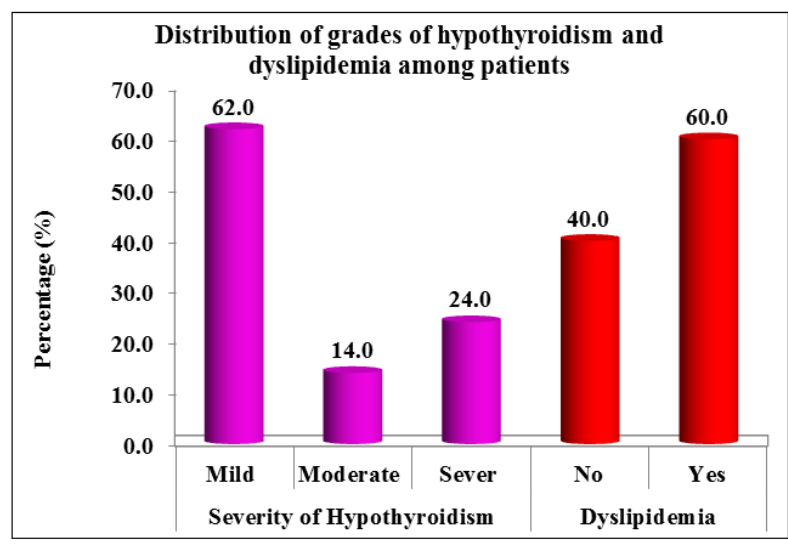

Table-3: Comparison of Total Cholesterol, Serum LDL and HDL of Patients among Three Grades of TSH

\begin{tabular}{|c|c|c|c|c|c|}
\hline \multirow[t]{2}{*}{ Lipid Parameter } & \multirow[t]{2}{*}{ Grading of TSH } & \multirow[t]{2}{*}{ Size } & \multirow{2}{*}{$\begin{array}{l}\text { Spread } \\
\text { Mean } \pm \text { SD }\end{array}$} & \multicolumn{2}{|c|}{ 95\% Confidence Interval for Mean } \\
\hline & & & & LB & UB \\
\hline \multirow{4}{*}{ Total Cholesterol (mg/dl) } & Mild & 31 & $165.68 \pm 53.65$ & 146.00 & 185.36 \\
\hline & Moderate & 7 & $215.00 \pm 7.19$ & 208.35 & 221.65 \\
\hline & Severe & 12 & $225.33 \pm 115.05$ & 152.23 & 298.44 \\
\hline & \multicolumn{5}{|c|}{$\mathrm{p}$-value $(\mathrm{LOS}): \mathrm{F}=3.77\left(\mathrm{p}<0.03^{*}\right)$} \\
\hline \multirow[t]{4}{*}{ Serum LDL (mg/dl) } & Mild & 31 & $103.26 \pm 50.44$ & 84.76 & 121.76 \\
\hline & Moderate & 7 & $118.29 \pm 1.70$ & 116.71 & 119.86 \\
\hline & Severe & 12 & $153.00 \pm 31.75$ & 132.83 & 173.17 \\
\hline & \multicolumn{5}{|c|}{ p-value $($ LOS $): F=5.76\left(p<0.006^{\#}\right)$} \\
\hline \multirow[t]{4}{*}{ Serum HDL (mg/dl) } & Mild & 31 & $41.65 \pm 1.85$ & 40.97 & 42.33 \\
\hline & Moderate & 7 & $36.29 \pm 10.63$ & 26.46 & 46.11 \\
\hline & Severe & 12 & $28.00 \pm 1.65$ & 26.95 & 29.05 \\
\hline & \multicolumn{5}{|c|}{ p-value $($ LOS $): F=47.12\left(p<0.001^{\#}\right)$} \\
\hline
\end{tabular}

Table-4: Comparison of Triglyceride and Ratio of LDL and HDL of Patients among Three Grades of TSH

\begin{tabular}{|c|c|c|c|c|c|}
\hline \multirow[t]{2}{*}{ Lipid Parameter } & \multirow[t]{2}{*}{ Grading of TSH } & \multirow[t]{2}{*}{ Size } & \multirow{2}{*}{$\begin{array}{l}\text { Spread } \\
\text { Mean } \pm \text { SD }\end{array}$} & \multicolumn{2}{|c|}{ 95\% Confidence Interval for Mean } \\
\hline & & & & LB & UB \\
\hline \multirow[t]{4}{*}{ Triglyceride (mg/dl) } & Mild & 31 & $163.39 \pm 63.99$ & 139.92 & 186.86 \\
\hline & Moderate & 7 & $239.43 \pm 5.09$ & 234.72 & 244.14 \\
\hline & Severe & 12 & $259.67 \pm 254.74$ & 97.81 & 421.52 \\
\hline & \multicolumn{5}{|c|}{$\mathrm{p}$-value $(\mathrm{LOS}): \mathrm{F}=2.66\left(\mathrm{p}<0.08^{\wedge}\right)$} \\
\hline \multirow[t]{4}{*}{ Ratio (LDL:HDL) } & Mild & 31 & $2.49 \pm 1.24$ & 2.04 & 2.94 \\
\hline & Moderate & 7 & $3.72 \pm 1.92$ & 1.94 & 5.50 \\
\hline & Severe & 12 & $5.51 \pm 1.38$ & 4.63 & 6.38 \\
\hline & \multicolumn{5}{|c|}{ p-value $(\operatorname{LOS}): F=21.09\left(\mathrm{p}<0.001^{\#}\right)$} \\
\hline
\end{tabular}


Snehal Mishra et al; Sch J App Med Sci, Mar, 2021; 9(3): 404-409

\section{ELECTROCARDIOGRAPHIC CHANGES IN HYPOTHYROIDISM}

The analysis of ECG changes among newly diagnosed hypothyroid patients reported that all $(100.0 \%)$ of the studied cases of newly diagnosed hypothyroid patients observed with regular rhythm and normal axes while effect on voltage of complexes found to be normal among $34.0 \%$.
The effect on voltage of complexes was found to be low voltage complex among $66.0 \%$ newly diagnosed hypothyroid patients whereas nonspecific ST-T wave abnormalities was seen in $8.0 \%$ cases of newly diagnosed hypothyroid cases.

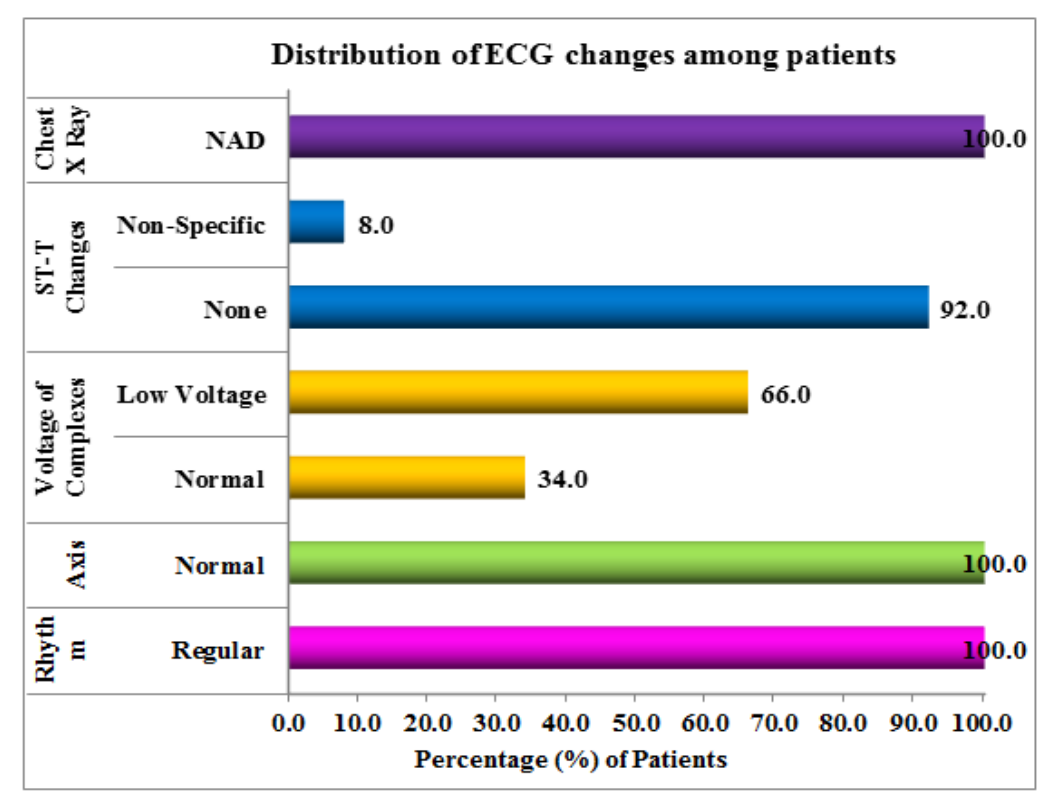

\section{DISCUSSION}

Worldwide, the most common cause for hypothyroidism is iodine deficiency. It is estimated that about 1 billion people worldwide suffer from iodine deficiency [10].

From the earlier research on hypothyroidism it is clear that both Lipid Profile and Electrocardiography play an important role in diagnosing the cardiac complications occurring in hypothyroidism.

The present study consisted of total 50 patients of hypothyroidism (newly diagnosed) and were evaluated for lipid abnormalities and Electrocardiographic Changes.

The study population consisted of males and females between the age group of 27-74 years and most patients were in the age group of $25-45$ years (48\%) and the mean age group of this study was 49.46 years.

Similarly A.V. Daphale et al., [11] found the mean age of study population to be $40.76 \pm 13.20$ with maximum number of patients in age group 45-59, and Behera BK et al., [12] in a study comprising 60 hypothyroid patients observed the mean age to be 42.45 years with majority of patients in age group 17-47 years.
In our study, there was a preponderance of female patients consisting of $82 \%$ of total study population while A.V. Daphale et al., [11] noted female preponderance with $85 \%$ of total patients, and Behera BK et al., [12] noted $76.7 \%$ female patients, while Ghosh et al., [13] noted $85 \%$ female preponderance.

In our study, $31(62 \%)$ patients who had TSH values less than $20 \mathrm{mIU} / \mathrm{mL}$ were mild hypothyroidism, around 7(14\%) patients had TSH of 20-50 $\mathrm{mIU} / \mathrm{mL}$ were classified as moderate hypothyroidism. Severe hypothyroidism with value $>50 \mathrm{mIU} / \mathrm{mL}$ was seen in12 $(24 \%)$ of cases while in a study conducted by M. Agila Saravanan et al., [14] found $24(34 \%)$ patients with mild, 29(41\%) with moderate and $17(24 \%)$ patients with severe hypothyroidism.

On analyzing the ECG changes in hypothyroid patients, the most common finding in our study was presence of Low voltage complex; accounting for $66 \%$ of population. Further this was also noted that the effect on voltage of complexes was found to be normal in $48.4 \%$ newly diagnosed hypothyroid patients who had mild grades of TSH as compared to moderate $(14.3 \%)$ and severe $(8.3 \%)$ grades of TSH. These differences in proportion with reference to grade of TSH was significantly $(p<0.03)$ associated with effect on voltage of complexes. 
Snehal Mishra et al; Sch J App Med Sci, Mar, 2021; 9(3): 404-409

Next most common finding was Sinus Bradycardia, noted in $26 \%$ patients. QTc interval was prolonged in $38 \%$ patients. However non specific ST-T wave abnormalities were seen in $8 \%$ cases and it was also noted that all the studied cases $(100 \%)$ had regular rhythm and normal axis.

Similarly in a study conducted by Behera BK et al., [12], most common ECG finding was Low Voltage complexes in $60 \%$ cases, $15 \%$ cases had ST-T changes and RBBB was noted in $29 \%$ cases. QTc prolongation was not noted in this study.

On the contrary, M. Agila Saravanan et al., [14] observed Sinus Bradycardia to be the most common ECG finding in $39 \%$ patients while Low Voltage Complexes in about $34 \%$ cases, least common findings were ST-T changes (9\%), RBBB (3\%) and LBBB (1\%).

Ghosh et al., [13] noted Sinus Bradycardia in $40 \%$ hypothyroid patients, low voltage complexes in $33 \%$ and non specific ST-T changes in $16.47 \%$ patients.

In our study, the average total cholesterol in newly diagnosed hypothyroid patients with severe TSH $(225.33 \pm 115.05 \mathrm{mg} / \mathrm{dl})$ was found to be significantly elevated as compared to those who had moderate $(215 \pm 7.19 \mathrm{mg} / \mathrm{dl})$ and mild $(165.68 \pm 53.65 \mathrm{mg} / \mathrm{dl})$ grades of TSH. However, these differences in mean total cholesterol among three grades of TSH were totally significant $(\mathrm{p}<0.03)$.

The mean serum LDL in our study $(153 \pm 31.75$ $\mathrm{mg} / \mathrm{dl}$ ) was found to be significantly higher as compared to those with moderate and mild grades of TSH and these differences were statistically highly significant $(\mathrm{p}<0.006)$.

The average serum HDL of newly diagnosed hypothyroid patients with severe $\operatorname{TSH}(28.00 \pm 1.65$ $\mathrm{mg} / \mathrm{dl}$ ) was found to be significantly smaller as compared to those who had moderate $(36.29 \pm 10.63$ $\mathrm{mg} / \mathrm{dl})$ and mild $(14.65 \pm 1.85 \mathrm{mg} / \mathrm{dl})$ grades of $\mathrm{TSH}$. However, these differences in mean HDL among three grades of TSH were highly significant $(\mathrm{p}<0.001)$.

Our study also projected that the Triglyceride level and ratio of LDL and HDL was significantly elevated in patients with severe grades of $\mathrm{TSH}$ as compared to mild and moderate grades.

Thus to summarise in our study, the total cholesterol, serum LDL and serum TG levels were significantly elevated but the serum HDL was significantly reduced among severe grades of TSH as compared with mild and moderate grades of TSH.

Similarly A. V. Daphale et al., [11] found that the mean total cholesterol (301.55 \pm 20.53), LDL cholesterol $(181.87 \pm 20.11)$ and TG $(216.49 \pm 20.72)$ were found significantly increased whereas HDL (30.55 \pm 7.29) was significantly decreased in overt hypothyroid patients.

In a study by Ghosh et al., [13], Lipid profile analysis showed increased total cholesterol, triglyceride, LDL, VLDL level, which had statistically significant relationship with increased TSH level $(\mathrm{P}=0.000, \mathrm{P}=$ $0.000, \mathrm{P}=0.000, \mathrm{P}=0.000$ respectively) and there were also statistically significant relationships of decreased HDL level $(\mathrm{P}=0.000)$ with increased TSH level.

In a study by Khan et al., [15] mean serum cholesterol, LDL cholesterol and triglyceride levels in hypothyroid patients were $241.56 \pm 60.05,151.96 \pm$ 59.60 and $212 \pm 100.73 \mathrm{mg} / \mathrm{dl}$ respectively with $\mathrm{p}$ values < 0.001 whereas HDL cholesterol was significantly decreased with $\mathrm{p}$ value $<0.05$ ).

Patel et al., [16] in his study noted that Serum cholesterol, LDL were higher $(\mathrm{P}<0.0001)$ and HDL $(\mathrm{P}<0.0001)$ was lower in Subclinical Hypothyroid patients $\quad($ mean $\pm \mathrm{SD}=199.9 \pm 27.8 \quad \mathrm{mg} / \mathrm{dl}$, $130.0 \pm 26.3 \mathrm{mg} / \mathrm{dl}, 44.2 \pm 9.1 \mathrm{mg} / \mathrm{dl}$ respectively).

\section{CONCLUSION}

Hypothyroidism is an endocrinopathy demarcated by lower level of circulating thyroid hormones and thus subsequent slowing down of various metabolic processes.

From our study, we concluded that Hypothyroidism has significant impact on both cardiovascular system as well as Lipid profile, being more common in female patients.

The commonest electrocardiographic change noted in our study was presence of Low voltage complex followed by sinus bradycardia. Qtc interval was also prolonged in significant no. of patients.

Mean cholesterol, serum LDL and serum TG levels were significantly elevated but the serum HDL was significantly reduced among severe grades of TSH as compared to mild and moderate grades of TSH and were statistically significant.

If significant impaction of hypothyroidism on lipid profile is proved and prompt hormonal replacement therapy initiated then chasing dyslipidemia per se is not recommended unless the latter being associated with ASCVD.

Hence, prompt diagnosis on the basis of classical symptoms \& signs of hypothyroidism in conjunction with relevant laboratory investigations and thus subsequent initiation of appropriate thyroid hormone replacement i.e. levothyroxine (T4) can minimize the associated cardiovascular morbidities. 
Snehal Mishra et al; Sch J App Med Sci, Mar, 2021; 9(3): 404-409

\section{REFERENCES}

1. Pranav S, Sandeep C, Mrunalini K. A Study of cardiovascular Changes in Newly Detected Hypothyroid patients. MVP Journal Of Medical Sciences, 2017;4(2),102-106.

2. Goyal V, Goyal S. A Study of Electrocardiographic changes in thyroid disorders. Int J Med Res Rev. 2016;4(4):486-490.

3. Rizos CV, Elisaf MS, Liberopoulos EN. Effects of thyroid dysfunction on lipid profile. Open Cardiovasc Med J. 2011;5:76-84.

4. Shekhar R, Srinivas CH, Das MC. Lipid profile in 'Newly Diagnosed' an 'On Treatment' hypothyroid. J Clin Diagn Res. 2011;5:998-1000.

5. Galetta F, Franzoni F, Fallahi P, Tocchini L, Braccini L, Santoro G, Antonelli A. Changes in heart rate variability and QT dispersion in patients with overt hypothyroidism. European journal of endocrinology. 2008 Jan 1;158(1):85-90.

6. Razvi S, Weaver JU, Vanderpump MP, Pearce $\mathrm{SH}$. The incidence of ischemic heart disease and mortality in people with subclinical hypothyroidism: Reanalysis of the Whickham Survey Cohort. J Clin Endocrinol Metab. 2010;10:1749.

7. Shah SK, Kilari M, Shah NK. Cross sectional study of cardiovascular manifestations of hypothyroidism. J Eval Med Dent Sci. 2013;2:5021-9.

8. Satpathy PK, Diggikar PM, Sachdeva V, Laddha M, Agarwal A, Singh H. Lipid profile and electrocardiographic changes in thyroid dysfunction. Med J DY Patil Univ. 2013;6:250-3.
9. K.Ramesh, Balaji Prasad Nayak. A Study of Cardiovascular involvement in Hypothyroidism. IAIM, 2016;3(5): 74-80.

10. Braverman LE, Cooper DS. Introduction to hypothyroidism. Chapter 34 in Werner and Ingbar's The Thyroid: A Fundamental and Clinical Text 10th Edition. Braverman LE, Cooper DS. Philadelphia: Lippincott Williams and Wilkins. 2013;523-524.

11. Daphale AV, Dhande NK. Study of Lipid Profile in Patients with Hypothyroidism. J Med Res Prac. 2017;6(4):141-143.

12. Behera BK, Satpathy A, Samal K. Cardiovascular changes in newly detected hypothyroid patients in Eastern India. Int J Res Med Sci. 2017 Oct;5(10):4302-6.

13. Ghosh A, Chaudhuri A, Ghosh S, Kanrar A, Adhya D, Pal K. Correlation of electrocardiographic and lipid profile changes in newly diagnosed hypothyroid subjects. Saudi J Sports Med. 2015;15:199-203.

14. Agila Saravanan M, Geetha S. A study of cardiovascular manifestation in patient with hypothyroidism. IAIM, 2018;5(9):67-73.

15. Khan MAH, Majumder I, Hoque MM, Fariduddin M, Mollah FH, Arslan MI. Lipid Profile in Hypothyroid Patients: A Cross Sectional Study. 2013;25(1).

16. Patel VI, Patel KP, Makadia MG, Shah AD, Chaudhari KS, Nilayangode HN. Study of serum lipid profile in subclinical hypothyroidism. Int $\mathbf{J}$ Biomed Adv Res. 2016;7:344-8. 